Supporting Information for

\title{
Mitochondrial Voltage-Dependent Anion Channel 1- Hexokinase-II Complex-Targeted Strategy for Melanoma Inhibition Using Designed Multi-Block Peptide Amphiphiles
}

Fan Zhang ${ }^{a}$, Angelina Angelova ${ }^{c}$, Vasil M. Garamus ${ }^{d}$, Borislav Angelov ${ }^{e}$, Shuyang Tu $u^{f}$, Liangliang Kong ${ }^{f}$, Xinlei Zhang ${ }^{a}, \mathrm{Na} \mathrm{Li}^{*}{ }^{*}$, and Aihua Zou ${ }^{* a, b}$

${ }^{a}$ Shanghai Key Laboratory of Functional Materials Chemistry, School of Chemistry and Molecular Engineering, East China University of Science and Technology,

Shanghai 200237, P. R. China, E-mail: aihuazou@shnu.edu.cn

${ }^{\mathrm{b}}$ College of Chemistry and Materials Science, Shanghai Normal University, Shanghai 200234, P. R. China

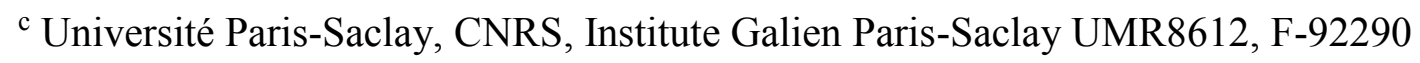
Châtenay-Malabry, France

${ }^{\mathrm{d}}$ Helmholtz-Zentrum Hereon, D-21502 Geesthacht, Germany

${ }^{\mathrm{e}}$ Institute of Physics, ELI Beamlines, Academy of Sciences of the Czech Republic, Na Slovance 2, CZ-18221 Prague, Czech Republic

${ }^{\mathrm{f}}$ National Facility for Protein Science in Shanghai, Shanghai Advanced Research Institute (Zhangjiang Laboratory), Chinese Academy of Sciences, Shanghai 201210, China, E-mail: nli@sibcb.ac.cn 
Table S1. Summary of the half maximal inhibitory concentration $\left(\mathrm{IC}_{50}\right)$ values $(\mu \mathrm{M})$ for cell death induction by the peptides Pal-N-Ter-TAT and Pal-pFL-N-Ter-TAT in various cancer cell lines. Cell lines were incubated with different peptide concentrations for $24 \mathrm{~h}$.

\begin{tabular}{|c|c|c|}
\hline Cell/IC 50 value of peptides $(\mu \mathrm{M})$ & Pal-N-Ter-TAT & Pal-pFL-N-Ter-TAT \\
\hline Human lung cancer A549 & 44.98 & 31.17 \\
\hline Human breast cancer MCF-7 & 27.26 & 11.85 \\
\hline Human malignant melanoma A375 & 36.67 & 6.96 \\
\hline
\end{tabular}

a)
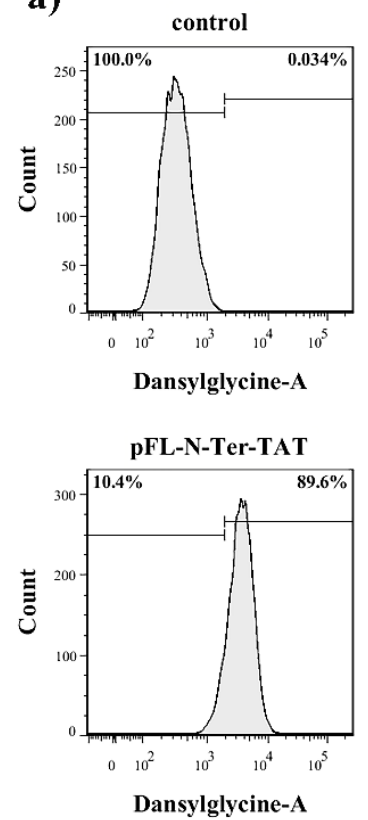

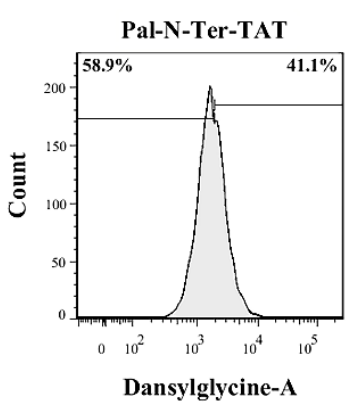

Pal-pFL-N-Ter-TAT

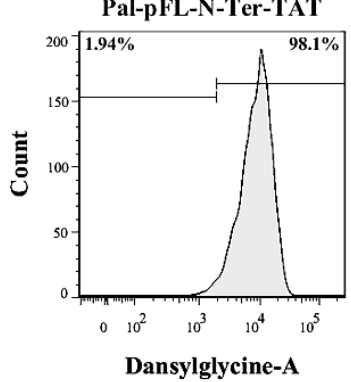

b)

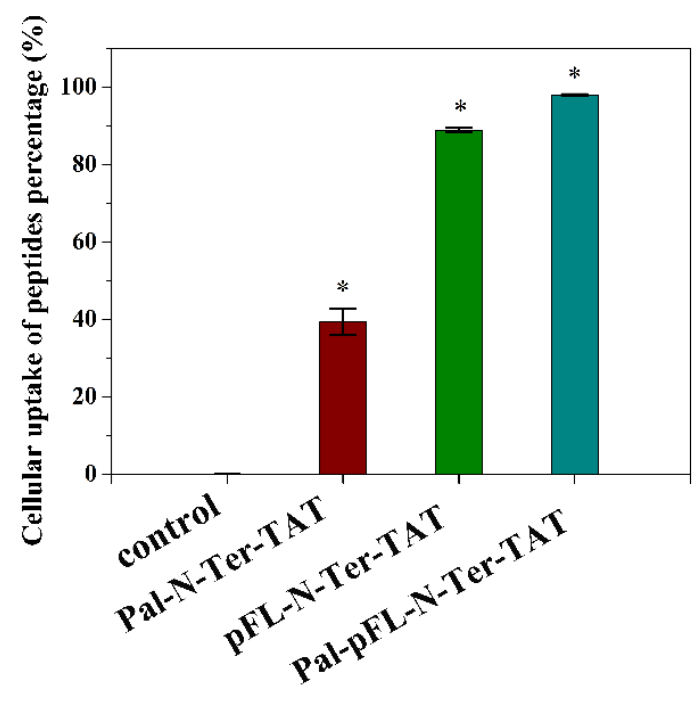

Figure S1. A375 cell uptake of Dansylglycine-labeled peptides by flow cytometry: a) A375 cells were incubated with $12.5 \mu \mathrm{M}$ Pal-N-Ter-TAT, pFL-N-Ter-TAT or Pal-pFL-N-Ter-TAT for $4 \mathrm{~h}$. The left represents cells that did not take up Dansylglycine-labeled peptides, while the right represents Dansylglycine-labeled peptides taken cells; b) A summary of cells percentage taken Dansylglycinelabeled peptides. Data were presented as mean $\pm \mathrm{SD}(\mathrm{n}=3)$. 

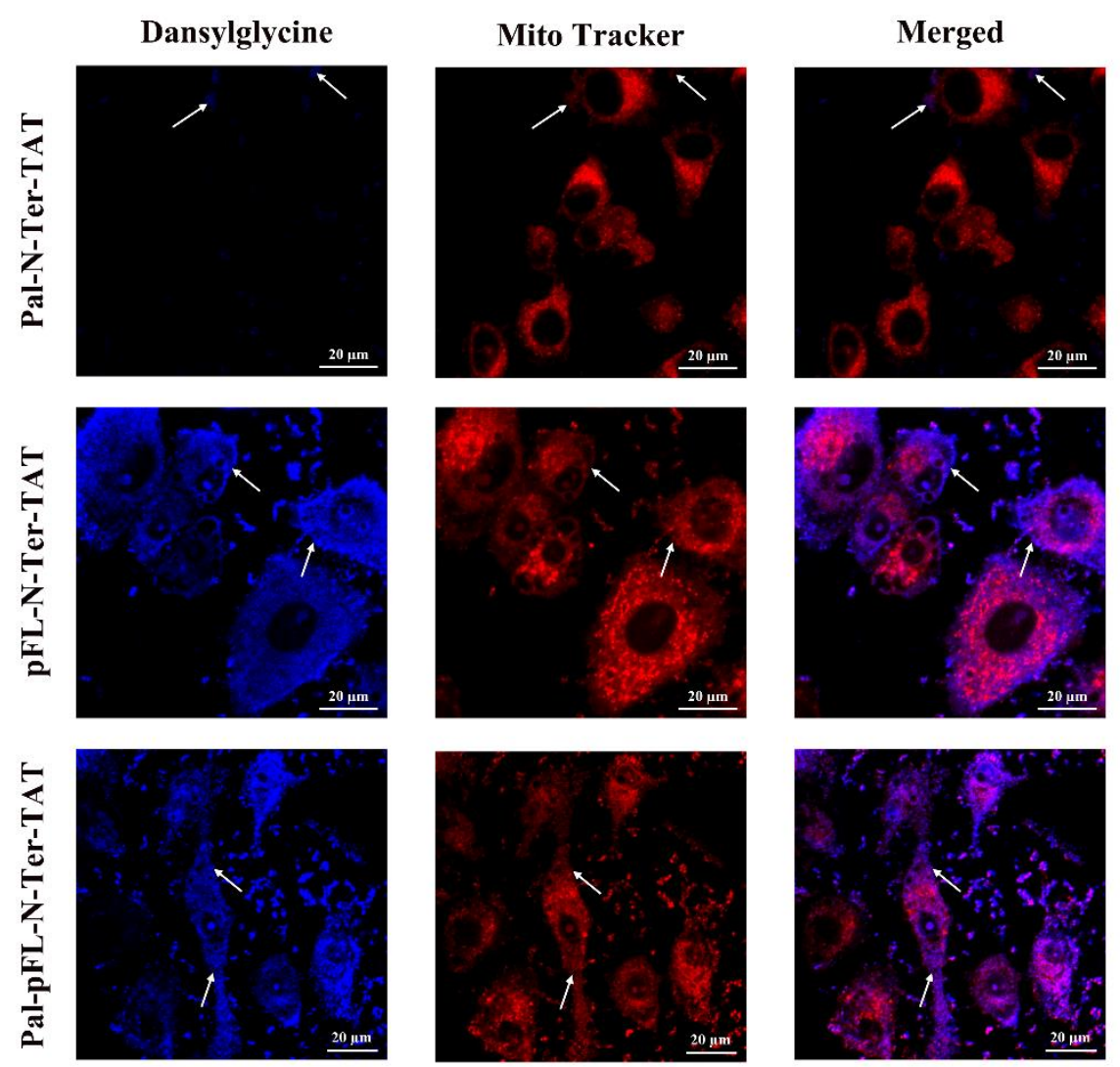

Figure S2. Confocal microscopy study of intracellular localization of peptides. A375 cells were incubated with $12.5 \mu \mathrm{M}$ Pal-N-Ter-TAT, pFL-N-Ter-TAT or Pal-pFL-N-Ter-TAT for $2 \mathrm{~h}$. The blue color indicates the fluorescence due to the uptake of the dansylglycine-labeled peptide. The red color is associated with the mitochondrial staining by $100 \mathrm{nM}$ MitoTracker Deep Red dye. The arrows indicate the co-localization established by the merged images. 